\title{
El gasto social como factor que favorece una mayor dependencia del IVA. Un análisis para el caso colombiano
}

Social Expenditure as a Factor that Promotes Greater Dependence on the VAT. Analysis of the Colombian Case

Víctor Mauricio Castañeda Rodríguez

Recibido: 10/03/2013

Aprobado: 22/05/2014

Universidad Jorge Tadeo Lozano, Bogotá, Colombia. [vmcastanedar@yahoo.es] 


\title{
184
}

El gasto social como factor que favorece una mayor dependencia del IVA.

Un análisis para el caso colombiano

VÍCTOR MAURICIO CASTAÑEDA RODRÍGUEZ

\section{Resumen}

Este documento, mediante un estudio de caso para Colombia sugiere que el gasto público social facilita el incremento de la participación de los impuestos indirectos como el IVA en el recaudo, no solo por el esfuerzo fiscal que requiere su financiación, sino también por el efecto de compensación que significa para los contribuyentes, particularmente aquellos de menores ingresos. Asimismo, se presenta evidencia acerca de los determinantes de la estructura y presión tributaria empleando datos del periodo 19702010, se resalta su dependencia temporal y se considera el efecto de las reformas tributarias aprobadas.

\section{Palabras clave}

Reformas tributarias; presión tributaria; estructura tributaria; gasto público social.

\begin{abstract}
This paper, through a Colombian case study, suggests that the public social expenditure helps increase the contribution that indirect taxes such as VAT has on revenue, not only due to the fiscal effort its funding requires, but also because of the compensation effect for taxpayers, particularly for those with a lower income. Evidence on the structure determinants and tax pressure using data for the 1970-2010 period is also presented, its temporal dependence is highlighted and the effect of adopted tax reforms is considered.
\end{abstract}

\section{Key Words}

Tax reform; tax pressure; tax structure; public social expenditure.

JEL Classifications: H2O; H29; 054. 
Ecos de Economía

Universidad EAFIT

No 38 - Vol. 18 / enero-junio 2014

\section{Introducción}

Colombia, en términos macroeconómicos, ha optado por una postura conservadora, sin padecer en su historia reciente de crisis económicas de la magnitud alcanzada en otros países de América Latina (AL). Por su parte, las reformas fiscales adoptadas en los ochenta y profundizadas en los noventa, por ejemplo en México y Argentina, se relacionaron con la necesidad apremiante de reducir el déficit fiscal y recuperar la confianza de los mercados de capitales, ello en un contexto de recesión que favoreció el incremento del impuesto al valor agregado (IVA) y la creación de beneficios tributarios en lo que respecta a los impuestos sobre la renta (ISR), bajo la motivación de incentivar la inversión y acelerar el proceso de recuperación .

Sin embargo, es interesante que Colombia haya emprendido reformas tributarias similares a las comentadas anteriormente, entre otras el aumento de la alícuota general de IVA del 10 al 16\% durante la primera mitad de los noventa, pese a no experimentar el sentido de urgencia que suele acompañar a un periodo de estrés económico. Así, mientras que en otros países una motivación de las reformas fue la atención de las recesiones, que demandaban recuperar un nivel de ingresos coherente con el gasto público inflexible en el corto plazo, en Colombia durante los últimos treinta años ellas han sido en parte el resultado de los intentos de los respectivos gobierno de financiar los incrementos del gasto, en muchos casos automáticos por la injerencia de reglas llevadas incluso al orden constitucional (e. g., Constitución de 1991).

Es decir que no hay una única causa para que la dinámica tributaria en la región, especialmente en cuanto a estructura, presente elementos comunes, como en el caso de la mayor dependencia de los impuestos indirectos de base interna y una menor progresividad, tanto horizontal como vertical. ${ }^{1}$ En Colombia, por ejemplo, el aumento del IVA no necesariamente se explica por el seguimiento de un recetario como el famoso Consenso de Washington, sino que dichas políticas se favorecieron con el incremento del gasto público social (en adelante GS), que pasó del 5,8 al 14,5\% del PIB entre 1991 y 1996; es más fácil que un Gobierno logre introducir una reforma regresiva si lo que se financia, al menos en parte, corresponde a erogaciones visibles para la sociedad, lo que además, si se materializa en mayor confianza en el sector público, incentiva a los contribuyentes

1 Bajo el principio de la capacidad de pago, se entiende por equidad horizontal al tratamiento igual para iguales, así como equidad vertical es el tratamiento diferente para diferentes. 


\section{6}

El gasto social como factor que favorece una mayor dependencia del IVA.

Un análisis para el caso colombiano

VÍCTOR MAURICIO CASTAÑEDA RODRÍGUEZ

a pagar los nuevos o mayores impuestos que les corresponden (véase e. g., Torgler \& Schneider, 2007; Torgler \& Schaltegger, 2005).

Este trabajo sugiere, entonces, que además de las crisis económicas que facilitan la adopción de medidas tributarias con cierta reputación internacional o que son blindadas por su aparente tecnicismo, existe un conjunto de factores adicionales que las favorecen; así, el GS se constituye en un argumento a tener en cuenta para establecer cuánto puede un país modificar su sistema tributario y de qué forma, tomando como referencia el caso colombiano. Esto significa un aporte en la materia, porque permite considerar elementos explicativos que de manera conjunta inciden en la suerte que corre un proyecto de reforma tributaria, según la aceptación que en general pueda recibir de la ciudadanía, y su cumplimiento cuando se convierte en ley.

Adicional a esta introducción, el artículo se divide en otras cinco partes. En la primera se discute un marco teórico que considera el tema de la moral tributaria para fundamentar la relación entre gasto público y tributación, particularmente en lo que atañe a la dependencia de impuestos regresivos como el IVA. Posteriormente, se describe la dinámica tributaria en Colombia entre 1980 y 2010, y se considera el contexto económico que la acompañó.

En la tercera sección se analiza la dinámica del GS en Colombia desde la década de los noventa, particularmente en lo que concierne a educación y salud, dada la disponibilidad de información y que la Constitución de 1991 generó un ajuste automático de estos rubros al alza. En la cuarta parte, con la intención de brindar soporte empírico, se amplía el periodo de análisis - desde la década de los setenta-y se estudia qué factores determinaron la dinámica tributaria del país, considerándose además los efectos de las reformas tributarias entre 1970 y 2010. Al final se presentan las conclusiones.

\section{El gasto público social como factor que favorece la aceptación de mayores impuestos y su concentración en aquellos de tipo indirecto}

Pese a que en ciencias económicas muchas veces es difícil sustentar determinada dirección de causalidad entre variables, lo cual no es la excepción en lo que se refiere a ingresos tributarios y gasto público, acá se sostiene que el GS es un factor que favorece la 
aceptación de incrementos de impuestos indirectos, por su visibilidad y porque supone una compensación en especial para aquellos contribuyentes que por sus condiciones económicas no accederían a bienes y servicios meritorios (e. g., educación) de no ser por la intervención del Estado. Y aunque habrá quienes digan que esto es una obviedad en el caso colombiano, pues en la primera mitad de los noventa la legislación tributaria aumentó las tasas del IVA e implementó tratamientos diferenciales para los ISR, esto se puede ver como una decisión fundamentada en el tipo de gasto que se financiaría, pues el grado de éxito de un proyecto de reforma, no solo depende de que sea aprobado, sino de que los contribuyentes estén dispuestos a aceptar mayores obligaciones fiscales.

El grado en que una medida impositiva, por ejemplo un aumento del IVA, se puede aplicar, depende mucho de la voluntad de los contribuyentes para cumplir la ley, y no únicamente de las acciones punitivas de la administración tributaria para desincentivar acciones como la evasión. Si los ciudadanos decidieran si pagan o no impuestos con base en un análisis costo-beneficio bajo riesgo, donde el costo está asociado a la probabilidad de ser auditado y castigado por evadir, entonces sería de esperar que los países exhibieran una menor presión tributaria (PT) que la observada, dadas las limitaciones de los Gobiernos para verificar el cumplimiento de todas las obligaciones fiscales de los gobernados (Torgler \& Schaltegger, 2005). No es sorprendente, entonces, que sea extensa la literatura que muestra las limitaciones propias de las estrategias concentradas en el castigo como medio para promover el cumplimiento tributario (véase e. g., Frey \& Feld, 2002).

Ante las dificultades del análisis económico tradicional, el estudio de la moral tributaria, vista como la motivación intrínseca a pagar impuestos (Torgler \& Schaltegger, 2005), permite justificar que además de las condiciones particulares de los contribuyentes (sociales, económicas, demográficas y culturales), también importa la evaluación que hacen del funcionamiento del Estado y su grado de confianza en las instituciones.

Sin embargo, esta primera parte por sí misma implica un aporte en la medida en que fundamenta una relación entre el GS y la participación del IVA en la PT, pues la literatura revisada toma la predisposición de los ciudadanos a pagar impuestos en general. Para ello es importante comentar inicialmente que las erogaciones en programas sociales, desde un enfoque normativo, se deberían concentrar inicialmente en aquellos sectores con las condiciones económicas más desfavorables, para después, si los recursos lo 


\section{8}

El gasto social como factor que favorece una mayor dependencia del IVA.

Un análisis para el caso colombiano

VÍCTOR MAURICIO CASTAÑEDA RODRÍGUEZ

permiten, buscar la universalización; así, es razonable que una parte importante de los beneficiarios del GS paguen el IVA, pero no necesariamente los ISR. ${ }^{2}$

Al respecto, autores como Alm y Martínez-Vázquez (2007) sostienen que el sector público debe esforzarse por ganar la confianza de los ciudadanos mientras, al mismo tiempo, implementa programas que atienden sus demandas, así sea de manera parcial e incompleta, para legitimar su intervención y contribuir a la emersión (o fortalecimiento) de una norma social en que pagar impuestos sea bueno. Otros autores, no obstante, manifiestan que la confianza en el Gobierno únicamente es necesaria cuando quienes pagan los costos de las políticas no reciben los beneficios (Hetherington, 2004, citado en Leonardo, 2011), punto que contribuye a fundamentar que el crecimiento del GS cuando es automático, caso observado en Colombia en la primera mitad de los noventa, favorece el aumento de los impuestos indirectos (e. g., IVA), pues es difícil lograr que los deciles más altos financien en su totalidad programas que no los benefician directamente.

En suma, no solo crear programas sociales auspicia el cumplimiento tributario y la aceptación de las obligaciones fiscales por parte de los ciudadanos, sino que también puede delimitar el tipo de reformas que auspicia el Gobierno cuando se trata de financiarlas. A continuación, con el ánimo de plantear la relación entre impuestos al consumo y gasto público de manera formal, pero sin las pretensiones de un desarrollo muy sofisticado, se presenta un sencillo modelo que toma algunos elementos del trabajo de Hettich y Winer (1988).

Supóngase la existencia de una función $f^{h}($.) que define la probabilidad de que un individuo en un grupo de contribuyentes $h=1$, ., $H$ acepte determinado esquema fiscal, es decir, que apoye la política tributaria del Gobierno y esté dispuesto a cumplirla. Entre otros factores (representados por un vector $X$ ), que incluso podrían ser de tipo sociodemográfico, se considera que $f^{h}($.) depende del gasto $(G)$ y de las tasas impositivas al consumo y a la renta que se le cobran a cada contribuyente en $h\left(t_{c h}\right.$ y $\left.t_{\text {ISRh }}\right)$. Además, es razonable

2 Según el Estatuto Tributario, las personas asalariadas con una base gravable (que es el ingreso bruto menos deducciones) menor o igual a 95 unidades de valor tributario -UVT- (o \$2.541.895 en 2013) no son sujetas de retención. Este monto permite pensar que a quienes se les retiene por concepto de ingresos laborales también pueden acceder a la provisión privada de servicios como la educación. Adicionalmente, y pese a que en Colombia no existe discriminación socioeconómica que evite que un rico pueda matricular a sus hijos en un colegio público, hay un proceso de autoexclusión por parte de las clases medias y altas; factores como el diferencial en calidad entre educación pública y privada contribuyen a esta decisión. 
pensar que esta función es creciente en $G$ y decreciente en las tasas impositivas, en particular en $t_{c h}$, por lo que el beneficio político de aumentar el gasto es compensado en parte por las medidas para financiarlo.

$$
f^{h}\left(G, t_{c h}, t_{I S R h}, X_{h}\right) / f^{h^{\prime}}(G)=\frac{\partial f^{h}}{\partial G}>0 \wedge f^{h^{\prime}}\left(t_{c h}\right)=\frac{\partial f^{h}}{\partial t_{c h}}<0
$$

Sin embargo, $f^{h^{\prime}}(G)$ y $f^{h^{\prime}}\left(t_{c h}\right)$ varían según las condiciones particulares de cada grupo, de modo que si, por ejemplo, $h$ reúne a ciudadanos con pocos recursos, entonces $G$ será más importante para este que para otros en una mejor situación económica (lo que hará que $f^{h^{\prime}}(G)$ crezca), así como los impuestos al consumo no durable lo afectarán en mayor grado, pues la propensión marginal a consumir decrece con el nivel de ingreso.

El problema del Gobierno es fijar las tasas impositivas (no negativas) que gravan al consumo y renta, tal que su aceptación sea máxima en cada grupo $h$ de contribuyentes. Por tanto, si la PT financia el gasto, entonces lo anterior se resume en:

$$
\begin{aligned}
& \max _{G, t_{c h}, t_{I S R h}} f^{h}\left(G, t_{c h}, t_{I S R h}, X_{h}\right) \\
& \text { s.a. } \sum_{h=1}^{H} n_{h}\left(t_{c h} c_{h}+t_{I S R h} y_{h}\right)=G
\end{aligned}
$$

donde $C_{h}\left(y_{h}\right)$ es el consumo (renta) de cualquier contribuyente en $h$ y $n_{h}$ es su tamaño (número de individuos en h); [3] es claramente la restricción presupuestal del Gobierno.

Las condiciones de primer orden para $G$ y $t_{c h}$, variables de interés acá, son:

$$
\begin{gathered}
\frac{\partial f^{h}}{\partial G}=\lambda \\
\frac{\partial f^{\prime \prime}}{\partial t_{c h}}+\lambda n_{h}\left(c_{h}+t_{c h} \varepsilon_{c h}\right)=0
\end{gathered}
$$

$\varepsilon_{c h}=\frac{\partial c_{h}}{\partial t_{c h}}<0$ es el efecto distorsión del impuesto al consumo. Por simplificación se asume que $\varepsilon_{c h}$ es constante en cada grupo $h$, aunque es más razonable que $\varepsilon_{c h}$ sea creciente, caso al que también aplican los resultados comentados más adelante.

Después de reemplazar [4] en [5], es fácil concluir que la respectiva tarifa óptima del impuesto al consumo está dada por: 


\section{0}

El gasto social como factor que favorece una mayor dependencia del IVA.

Un análisis para el caso colombiano

VÍCTOR MAURICIO CASTAÑEDA RODRÍGUEZ

$$
t_{c h}^{*}=\frac{c_{h}}{\left|\varepsilon_{c h}^{*}\right|}-\frac{\left|\frac{\partial f^{h}}{\partial t_{c h}^{*}}\right|}{\frac{\partial f^{h}}{\partial G}\left|\varepsilon_{c h}^{*}\right|}
$$

donde las expresiones entre barras representan valores absolutos. Aunque la expresión para $t_{I S R h}^{*}$ sigue una forma funcional similar a [6], se debe destacar que esto mismo hace que en lo macroeconómico no se pueda esperar un efecto significativo del gasto sobre la participación de los ISR en la PT, pues estos tienden a concentrarse en los individuos con más recursos, para quienes el GS no es tan importante.

De [6] se extrae que entre mayor sea $\frac{\partial f^{h}}{\partial G}$ también lo será la respectiva tarifa impositiva al consumo que se cobra a $h$, lo cual sustenta la experiencia de América Latina (AL) y Colombia, en particular, durante los noventa. El crecimiento de las alícuotas del IVA coincidieron con aumentos del GS, que a su vez explicaron en buena parte la subida del gasto total, de suerte que si existían amplias necesidades insatisfechas de la población que podían ser atendidas por el Estado, había también una motivación para financiar los respectivos programas sociales a través de los impuestos al consumo, más aún cuando Ios ISR han tendido a concentrarse en contribuyentes que no tienen que acudir a la provisión pública para acceder a servicios como la educación y la salud, y por tanto no experimentan la misma utilidad de su provisión pública que los pobres.

En términos más formales, el efecto de G sobre $t_{c h}^{*}$ depende de la curvatura de $f^{h}($.). Si $\frac{\partial f^{h}}{\partial G}$ crece cuando G lo hace, el efecto será positivo; la relación será negativa en el caso opuesto. Es decir que en los tramos en que sea convexa (cóncava) en G se puede esperar una asociación positiva (negativa) entre ambas variables; por lo que si se tiene en cuenta que en los noventa las necesidades insatisfechas de la población colombiana pobre eran bastantes, aunque aún lo siguen siendo, y el monto de GS era reducido, entonces es prudente anticipar que las partidas destinadas a financiar programas sociales delimitaron su financiación en los impuestos al consumo, esto como una decisión racional del Gobierno. La proposición 1 fundamenta estos comentarios.

Proposición 1: Existe una asociación directa entre la utilidad que representa el gasto para un grupo $h$ y la tasa efectiva al consumo que se le cobra a sus miembros. Por otra parte, un aumento de G estará acompañado de una subida (reducción) de $t_{c h}^{*} \mathrm{si} \frac{\partial f^{h}}{\partial G}$ es creciente (decreciente). 
Prueba

De [6] se obtiene que: $\frac{\partial t_{c h}^{*}}{\partial u_{h}}=\frac{\left|\frac{\partial f^{h}}{\partial t_{c h}^{*}}\right|}{u_{h}^{2}\left|\varepsilon_{c h}^{*}\right|}>0$, con $u_{h}=\frac{\partial f^{h}}{\partial G}$. La segunda parte de la proposición es una implicación inmediata de esto.

Por supuesto, para que el cambio de las tasas efectivas de tributación guarde una relación directa con el peso de los respectivos impuestos en la PT, la economía debe estar en la sección creciente de la curva de Laffer, lo cual es razonable acá porque no tendría sentido aumentar un impuesto si con ello se reducen los recursos para financiar el gasto. Además, cabe aclarar que en este documento se hace énfasis en el GS porque es la partida funcional más visible para la sociedad y en la primera mitad de los noventa, cuando más aumentó la participación del IVA en la PT, fue la principal fuente de crecimiento del gasto público total.

\section{La política tributaria en Colombia en el periodo 1980- 2010: la evolución de la presión y estructura tributaria}

Colombia mostró una tendencia a aplicar el mismo tipo de políticas tributarias promovidas en otros países de AL tras la crisis de la deuda externa, pero en un escenario diferente. Es cierto que desde finales de los setenta empezó a crecer el déficit (figura 1), alcanzando su máximo valor para el sector público no financiero (SPNF) en 1983, pero ello no coincidió con una presión excesiva sobre la cuenta de capitales. Edwards y Steiner (2000) Ilaman la atención sobre este punto, especialmente para las reformas económicas emprendidas durante la administración de Gaviria (1900-1994).

Por su parte, la Constitución de 1991 creó un nuevo régimen de transferencias y limitó el financiamiento a través del Banco de la República, lo cual significa que se incentivó el aumento de las partidas del gasto y se restringieron las opciones para financiarlas, presionando así la presentación de proyectos para incrementar la PT, pero en escenarios económicos no necesariamente adversos.

El comportamiento relativamente estable de la economía colombiana ha condicionado generalmente la presentación de las reformas tributarias al comportamiento efectivo o esperado del resultado fiscal, afectado por el crecimiento del gasto público. Sin embar- 


\section{2}

El gasto social como factor que favorece una mayor dependencia del IVA.

Un análisis para el caso colombiano

VÍCTOR MAURICIO CASTAÑEDA RODRÍGUEZ

go, esto no ha permitido dar el carácter de urgencia a los proyectos de ley presentados, lo que asimismo ha dificultado alcanzar el grado de consenso necesario para aprobar leyes fieles a las versiones iniciales de sus proyectos (Castañeda, 2013; Clavijo, 2005). No es extraño, entonces, que sean numerosas las reformas realizadas al Estatuto Tributario (ET) colombiano desde 1980 (16 considerando únicamente las más importantes).

\section{Figura 1.}

Déficit o superávit (con privatizaciones) como proporción del PIB entre 1970 y 2011

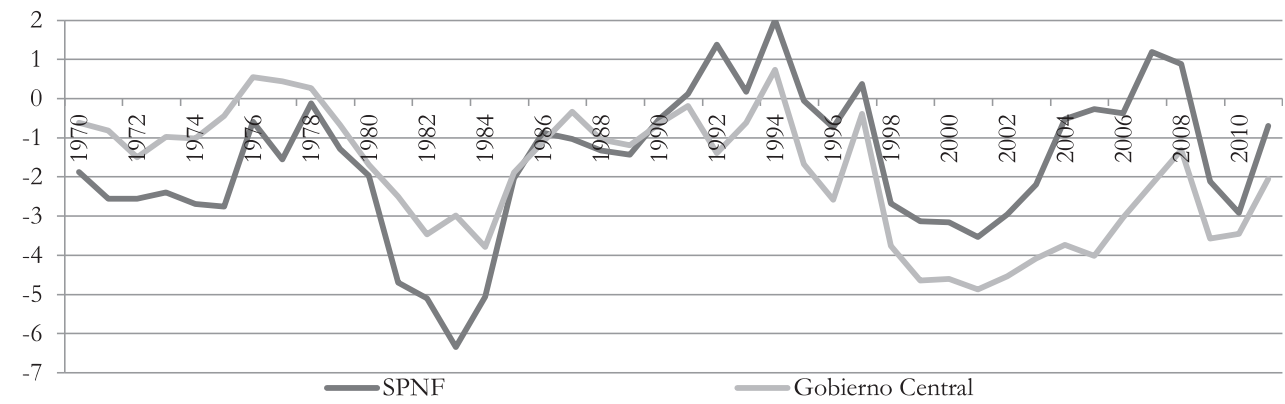

Fuente: elaboración propia con base en datos del Banco de la República. La dinámica del resultado fiscal sin privatizaciones difiere del reportado acá desde 1994, y las respectivas curvas, tanto para el SPNF como para el Gobierno central, por supuesto, se ubican por debajo de las que aparecen en esta figura.

Aunque no se cuenta con el espacio suficiente para hacer una presentación detallada de las principales reformas tributarias nacionales aprobadas entre 1982 y 2010, se aconseja al lector interesado en su estudio que consulte, entre otros, a Olivera, Pachón y Perry (2010); Junguito y Rincón (2004); y Calderón y González (2002). Además de la evidente frecuencia con que se ha modificado la ley tributaria, es claro que gradualmente se ha buscado incrementar el recaudo a través del IVA; en la primera mitad de los noventa con alzas de su tarifa general y la ampliación de las bases, para posteriormente, dada la intervención de la Corte Constitucional con implicaciones fiscales (Wiesner, 2004), procederse a crear tarifas particulares para gravar determinados bienes y servicios. Por su parte, para los ISR abundan los tratamientos diferenciales, que en aras de incentivar la inversión y el empleo han perforado sus bases y potencial de recaudación aunque no exista evidencia de que hayan contribuido al logro de tales objetivos (Galindo \& Meléndez, 2010). 
Ecos de Economía

Universidad EAFIT

La tendencia de las reformas tributarias, por lo menos en su forma, sugiere que se optó por incrementar las tasas y bases del IVA, para con el mayor recaudo financiar reducciones de los impuestos directos y un conjunto de gastos visibles (e. g., el programa Familias en Acción). Además, su timing ha dependido del comportamiento efectivo o esperado de los resultados fiscales; por ejemplo, la reforma tributaria de 1983, en la administración de Belisario Betancur, se dio en un contexto de agudo déficit fiscal (figura 1), así como las correspondientes a la administración de Gaviria en 1990 y 1992 obedecieron al aumento anticipado del gasto público relacionado con las demandas de la Asamblea Constituyente y la insuficiencia para responder a su crecimiento real tras la aprobación de la Constitución de $1991{ }^{3}{ }^{3}$ respectivamente.

Por otra parte, el mayor gasto público en áreas como la educación y la salud, especialmente durante el periodo 1991-1996, junto al aumento de su cobertura, según se discute en la siguiente sección, facilitó en su momento la aprobación de las reformas que fundamentaron una mayor dependencia del IVA, en la medida en que redujo las presiones de modificación que normalmente se generan en su paso por el legislativo y presumiblemente motivó el cumplimiento de los contribuyentes, bajo los argumentos expuestos en la primera parte del documento.

Sin embargo, las reformas de los últimos años, particularmente desde la segunda mitad de los noventa, han sido una colcha de retazos de los proyectos de ley iniciales (Castañeda, 2013; Clavijo, 2005), lo que permite inferir que sus efectos sobre la dinámica tributaria han sido poco significativos, si se tiene en cuenta la influencia de variables estructurales como lo es el PIB per cápita, que sirve de proxy del desarrollo de la economía, o el incremento del gasto público (particularmente el GS), que facilita el cumplimiento tributario al reforzar la relación de reciprocidad entre el Estado y la sociedad (Torgler, 2005). Al respecto, otros trabajos, como el de García y Gómez (2005), quienes emplean un modelo de series temporales sobre tres indicadores (ingresos tributarios como porcentaje del PIB, ingresos tributarios reales e ingresos tributarios reales per cápita), concluyen que son pocas las reformas que empíricamente están relacionadas con un crecimiento de la PT; para García y Gómez (2005) solamente dos, la de 1974 y la de 1990.

3 Además de los previsibles incrementos del gasto que implicaba la aprobación de un sistema pensional dual (Ley 100 de 1993), que al reducir el número de aportantes al Instituto de Seguros Sociales (ISS) dejaba sin financiamiento el pago de las pensiones asignadas por este y los bonos pensionales de quienes se trasladaran el sistema de ahorro individual. 


\section{4}

El gasto social como factor que favorece una mayor dependencia del IVA.

Un análisis para el caso colombiano

VÍCTOR MAURICIO CASTAÑEDA RODRÍGUEZ

La figura 2 presenta la evolución de la estructura y PT, sin aportes a la seguridad social (SS), del Gobierno Central durante el periodo 1980-2011, pues sus estadísticas son de más fácil acceso que las del Gobierno General y representan cerca del $82 \%$ del nivel de recaudación de la nación, según datos de la Comisión Económica para América Latina y el Caribe (Cepal) entre 1990 y 2011; buena parte del comportamiento de la tributación en el país se explica por lo que ocurre a nivel central.

\section{Figura 2.}

Estructura (eje izquierdo) y presión tributaria (eje derecho) del Gobierno central colombiano entre 1980 y 2011

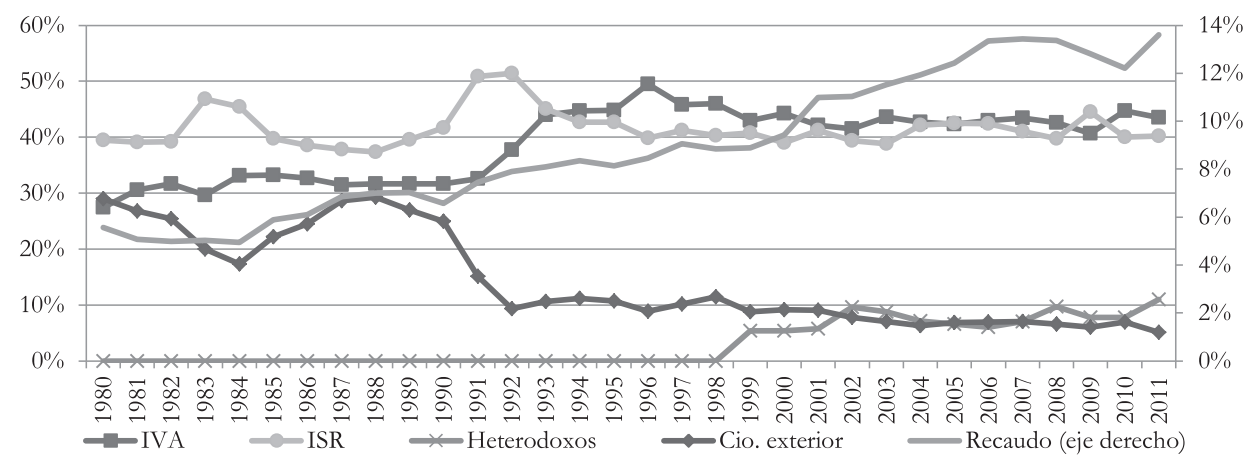

Fuente: elaboración propia con base en datos de la Dirección de Impuestos y Aduanas Nacionales (DIAN). El IVA corresponde tanto a las actividades internas como externas y bajo el nombre de "heterodoxos" se incluyen el impuesto al patrimonio y el gravamen a los movimientos financieros (GMF).

Se constata una serie de regularidades que, según se analizó al comienzo de esta sección, son comunes en AL (véase e. g., Cetrángolo \& Gómez-Sabaini, 2007; Sánchez, 2006), caso del mayor peso relativo ganado por el IVA, que contrasta con lo ocurrido para los impuestos al comercio internacional. Se observa que la PT creció de manera significativa entre 1990 y 2008, duplicándose en este lapso, y que la mayor parte de ese incremento tuvo como fuente al IVA. ${ }^{4}$

4 Su participación en la PT (sin SS) del Gobierno central pasó del 31,6 al 49,5\% entre 1990 y 1996. 


\section{Un breve análisis de lo ocurrido con el gasto público en los últimos años como dinamizador de la tributación}

Anteriormente se argumentó que una diferencia entre el proceso de reformas tributarias seguido en Colombia y otros países de AL en los últimos treinta años fue el contexto económico en que se aprobaron, pues en el primero no se correspondieron, en general, con la atención del Gobierno a una recesión económica. Si bien esto podría haber sido una oportunidad, si se siguen los argumentos de Rosas (1990) para explicar los avances en términos estructurales de la reforma de 1986, al suponer una mayor planeación por parte del ejecutivo para presentar proyectos consistentes al Congreso, en la práctica no fue así.

Entre tanto, se sostiene que el GS ayuda a explicar el comportamiento que se presenta en la figura 2, e incluso pudo desempeñar un papel facilitador compartido con el del contexto económico para que otros países de la región también aumentaran notablemente el IVA entre los años ochenta y noventa (véase e. g., Castañeda, 2012), al generar una oportunidad para las diferentes administraciones a la hora de defender reformas tributarias regresivas.

La figura 3 muestra, para el SPNF, que entre 1991 y 1996 el GS creció de manera importante, explicando a su vez la dinámica del gasto total, para posteriormente estancarse alrededor del 12,2\% del producto interno bruto (PIB). Sin embargo, fue hasta 2001, como resultado de la normatividad aprobada para imponer límites al déficit fiscal (especialmente en el ámbito regional), que se logró frenar el proceso de ampliación del Estado, el cual desde 1997 se fundamentó en rubros como el funcionamiento. Así, en los noventa el gasto siguió el comportamiento del PIB per cápita, según lo establece la ley de Wagner, pero fue en la primera mitad de la década que ello tuvo un correlato en el área social; lo curioso es que fue también entre 1991 y 1996 que el recaudo del IVA aumentó en un $70 \%$, lo que sugiere considerar si tal fenómeno se favoreció, al menos en parte, de lo primero.

Al respecto, Iregui, Melo y Ramos (2007) encuentran que se han dado avances en términos de cobertura en la educación primaria y secundaria (figura 4), lo cual se corresponde con el incremento de los recursos apropiados para este rubro entre 1991 y 1996, pero subsisten problemas de calidad que se materializan en las diferencias en el rendi- 


\section{6}

El gasto social como factor que favorece una mayor dependencia del IVA.

Un análisis para el caso colombiano

VÍCTOR MAURICIO CASTAÑEDA RODRÍGUEZ

miento, medido por pruebas nacionales como Saber 11 (antes Ilamado Icfes), ${ }^{5}$ entre los estudiantes de las instituciones públicas y privadas, fenómeno aún más marcado en las zonas rurales. Son muy pocos los colegios oficiales que se clasifican, de acuerdo con los resultados de sus estudiantes, en los grupos "muy superior" y "superior", en comparación con sus pares no oficiales (véase Icfes, 2011).

Figura 3.

Evolución del gasto público y del PIB per cápita entre 1990 y 2010

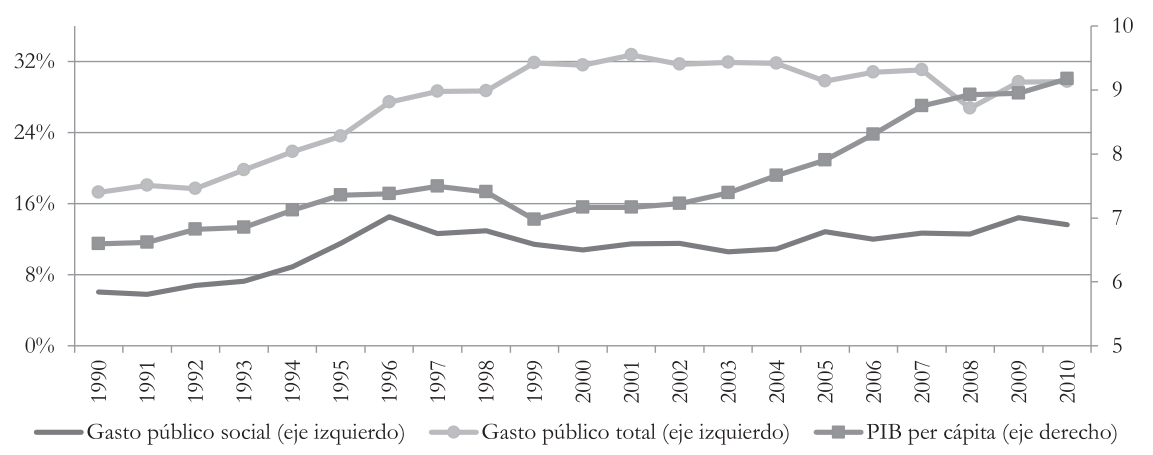

Fuente: elaboración propia con base en datos de la Cepal y del Banco Mundial. EI PIB per cápita está expresado en millones de pesos constantes de 2005 y el gasto como proporción del PIB.

Si bien existe un diferencial entre la educación pública y privada, especialmente en el nivel secundario, no por ello el aumento de su cobertura deja de ser importante como un elemento de movilización social y motivación para generar un mayor cumplimiento tributario, especialmente de aquellos contribuyentes cuyos hijos o familiares antes eran excluidos del sistema educativo.

El panorama no cambia en relación con la salud, pues aunque ha aumentado la cobertura ${ }^{6}$ (tabla 1), todavía existen deficiencias en la prestación del servicio (Agudelo, Cardona,

5 Este es un examen creado hace 44 años y cuyo propósito inicial fue ayudar a las instituciones de educación superior en sus procesos de admisión, además de crear criterios para el otorgamiento de beneficios (e. g., becas). Es obligatoria su presentación para los estudiantes en undécimo grado y las áreas del conocimiento que se evalúan se agrupan en dos conjuntos, núcleo común (lenguaje, matemáticas, biología, química, física, ciencias sociales, filosofía e inglés) y componente flexible (profundización e interdisciplinarias).

6 Aunque sin que ello coincidiera con las expectativas del Gobierno en su momento, pues hacia 1993 se esperaba alcanzar la cobertura universal en un término de diez años y que el $70 \%$ de esta quedara a cargo del régimen contributivo. 
Ecos de Economía Universidad EAFIT No 38 - Vol. 18 / enero-junio 2014

Ortega y Robledo, 2011). No obstante la insostenibilidad fiscal del sistema, ${ }^{7}$ algunos indicadores que ayudan a tener una idea del efecto del incremento del gasto público en este rubro, como la expectativa de vida al nacer y la tasa de mortalidad infantil, ${ }^{8}$ dan cuenta de un relativo éxito en la materia.

Figura 4.

Matrícula bruta por nivel de estudio entre 1980 y 2010

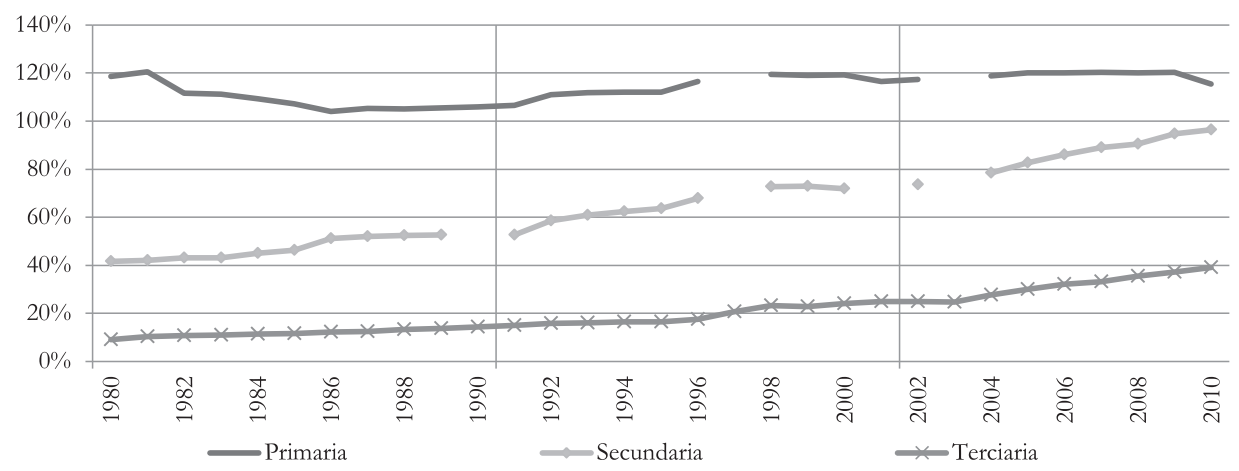

Fuente: elaboración propia con base en datos del Banco Mundial. Se utilizan las series de matricula bruta dado que son las más completas y las conclusiones básicas que se obtienen son las mismas que con las series de matrícula neta.

Tabla 1.

Población total y afiliada al sistema general de seguridad social en salud (1993-2009)

\begin{tabular}{c|c|c|c|c|c|c}
\hline Población total & $\mathbf{1 9 9 3}$ & $\mathbf{1 9 9 7}$ & $\mathbf{2 0 0 0}$ & $\mathbf{2 0 0 3}$ & $\mathbf{2 0 0 6}$ & $\mathbf{2 0 0 9}$ \\
\hline Total afiliados al SGSSS \% & 23,7 & 57,1 & 56,5 & 61,3 & 82,7 & 93,4 \\
\hline Régimen contributivo \% & 22,4 & 38,9 & 32,9 & 33,0 & 33,4 & 37,8 \\
\hline Régimen subsidiado \% & - & 18,2 & 23,6 & 28,4 & 45,0 & 51,1 \\
\hline Régimen excepción \% & & 0,0 & 0,0 & 0,0 & 4,3 & 8,7 \\
\hline No afiliados \% & 76,3 & 42,9 & 43,5 & 38,7 & 17,3 & 6,6 \\
\hline
\end{tabular}

Fuente: Agudelo et al. (2011).

7 Generada por la composición de afiliaciones, que se concentra en el régimen subsidiado, el reconocimiento de tutelas y la autorización de recobros por parte de los comités técnico-científicos, estas últimas dos causas especialmente importantes desde 2009 (Agudelo et al., 2011).

8 Según datos del Banco Mundial, las expectativas de vida al nacer pasaron entre 1993 y 2010 de 68,9 a 73,4 años, mientras que la tasa de mortalidad infantil cayó de 25,6 a 15,8 niños menores de un año muertos por cada 1.000 nacimientos. 


\section{8}

El gasto social como factor que favorece una mayor dependencia del IVA.

Un análisis para el caso colombiano

VÍCTOR MAURICIO CASTAÑEDA RODRÍGUEZ

Así, y pese a que persisten fenómenos y prácticas por corregir, entre otras la potencial influencia de intereses políticos en la determinación por parte de los beneficiarios del sistema subsidiado de salud (Gaviria, Medina \& Mejía, 2006), se ha avanzado en términos de cobertura; esto contribuye al establecimiento de unas bases morales que motivan el pago de impuestos, pues existe una compensación visible como el acceso al servicio, lo que está en línea con Torgler (2005, p. 137, traducción libre), quien sostiene que "los contribuyentes están más dispuestos a cumplir con la ley si el intercambio entre los impuestos que pagan y los servicios que presta el Gobierno se juzga como justo".

Ahora bien, se ha analizado el GS con énfasis en dos de sus componentes (educación y salud), por las limitaciones de espacio y porque esta sección es ilustrativa. Sin embargo, para tener una panorámica general, la figura 5 presenta la evolución del GS desagregándolo en cuatro áreas, sumando seguridad social (SS) y vivienda a las ya analizadas. A excepción del gasto en vivienda, los demás rubros han sido más dinámicos y exhibieron un patrón de crecimiento aproximadamente hasta 1996, para posteriormente caer (la tendencia cambió nuevamente en 1999 para la SS).

\section{Figura 5.}

Gasto social en educación, salud, seguridad social y vivienda como porcentaje del PIB (1990-2010)

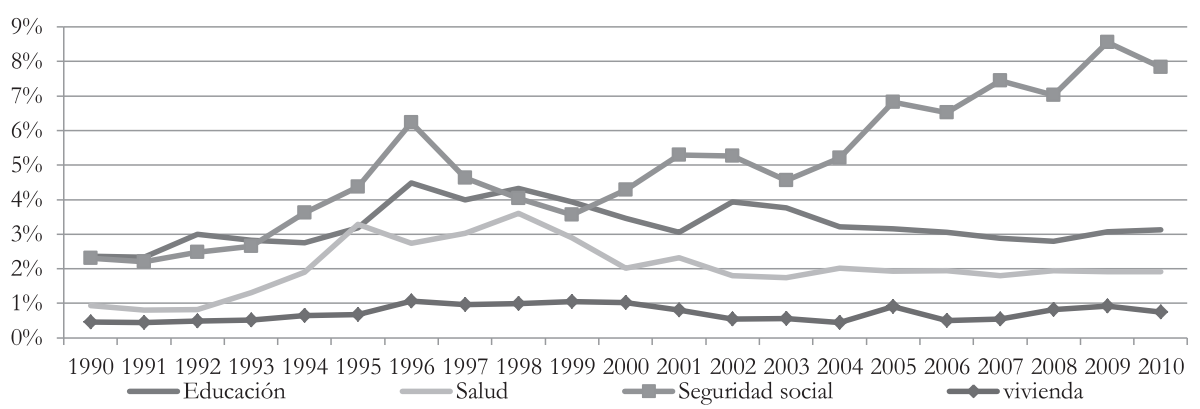

Fuente: elaboración propia con base en datos de la Cepal.

Dejando de lado el tema de la calidad en la ejecución del GS, se puede argüir que el Estado colombiano ha ganado mayor visibilidad en la vida de los ciudadanos, en especial durante la primera mitad de los noventa, de manera que si las decisiones de los agentes sobre cumplimiento tributario dependen de qué tan justa evalúan la relación Estado-so- 
Ecos de Economía

Universidad EAFIT

ciedad, entonces se podría esperar una incidencia positiva del GS sobre la participación del IVA en la PT, pues lo deben pagar tanto ricos como pobres, en particular aquellos que se benefician más de los programas sociales.

Por otra parte, para los impuestos directos (e. g., ISR) lo anterior pierde validez, ya que un mayor gasto público en campos específicos como la educación básica no es de tanta utilidad para los contribuyentes de las clases medio-altas y altas, quienes además no se encuentran excluidos de estos servicios por el mercado, por lo menos en periodos de auge económico (véase López \& Núñez, 2007). Además, la mayor parte de su recaudo obedece al pago de las personas jurídicas, sobre las cuales el control fiscal es mayor y reduce su grado de discrecionalidad.

Aunque acá no se analiza la distribución del gasto, en otros trabajos se destaca que con excepción de unas pocas partidas, como pensiones y educación terciaria, ${ }^{9}$ el GS es en general capturado en una mayor proporción por los deciles de menores ingresos (véase e. g., Moller, 2012; López \& Núñez, 2007), lo cual soporta la idea de que este delimita el grado en que se puede concentrar el recaudo en impuestos indirectos, caso del IVA.

La relación entre el Estado y la sociedad se da en un escenario de intercambio en que cada contribuyente decide sobre su cumplimiento tributario, no solo con base en argumentos como la probabilidad de ser identificado y castigado si evade, sino también de lo que recibe a cambio (compensación). Al analizar trabajos que presentan estimaciones de la evasión en horizontes temporales relativamente largos, por ejemplo el de Steiner y Soto (1998), para el caso del IVA, o el de Avendaño (2005), relativo al impuesto sobre la renta personal (ISRP), se encuentra además de una tendencia decreciente, en parte por la importancia que le han dado algunas reformas a su control (e. g., leyes 223 de 1995 y 788 de 2002), una relación inversa si se compara su dinámica con la del GS.

9 Según López y Núñez (2007, p. 209), en su análisis de la incidencia del GS en 2003, "si se excluyen los subsidios pensionales [...] y los otorgados a la educación superior [...], el resto [...] va en 73,2\% a la población pobre". 
El gasto social como factor que favorece una mayor dependencia del IVA.

Un análisis para el caso colombiano

VÍCTOR MAURICIO CASTAÑEDA RODRÍGUEZ

\section{Ejercicio empírico: determinantes de la estructura y el recaudo tributario en Colombia desde 1970}

En esta sección se analiza si lo discutido anteriormente, caso del GS como factor explicativo de algunos hechos estilizados de la tributación en Colombia (particularmente la mayor dependencia del recaudo en el IVA), tiene asidero empírico. Se considera un conjunto de regresiones dinámicas por MCO (Mínimos Cuadrados Ordinarios) que incorporan otras variables de control, de tipo económico, político y social; esto fundamentado en la literatura que analiza los determinantes de la tributación (véase, entre otros, a Castañeda, 2012, quien estudia el tema desde la retórica, o en términos empíricos a Dioda, 2012; Mahdavi, 2008; Bird, Martínez-Vázquez \& Torgler, 2008; Gupta, 2007; Davoodi \& Grigorian, 2007; Bahl, 2004). Además de establecer si las reformas tributarias entre 1970 y 2010 tuvieron algún efecto en el sistema impositivo, usando algunas dummies de intervención, se analiza el comportamiento de la PT y la participación de los ISR en la recaudación aprovechando los datos a los que se tiene acceso, aun cuando ello no sea indispensable para cumplir con el objetivo central de esta investigación.

Se consideran cuatro variables como endógenas: las participaciones del IVA - de fuente interna y externa- (\%IVA) y de los ISR (\%ISR) en la PT, ${ }^{10}$ además de esta y la probabilidad de una reforma con efectos sobre \%IVA (Reforma). La periodicidad de los datos es anual y se abarca el periodo 1970-2010; las fuentes de información son: DIAN, Banco Mundial, Banco de la República, Departamento Nacional de Planeación (DNP) y Polity IV. Si bien se consideraron diferentes especificaciones, por cuestión de espacio únicamente se presentan algunos resultados, en particular los que mejor ajuste presentaron en las regresiones con y sin variables de intervención.

Pese a que una revisión de las variables dependientes podría sugerir la utilización de series de tiempo, tal y como lo hacen, por ejemplo, García y Gómez (2005), ${ }^{11}$ se optó por emplear modelos dinámicos, que corresponden a la inclusión de variables tanto contemporáneas como rezagadas. Si bien se denota un path dependence que genera

10 Es poco común que los trabajos empíricos analicen la estructura tributaria en términos de la participación de cada fuente en el recaudo; por lo general lo que analizan es el recaudo que se obtiene de cada fuente. Sin embargo, acá se evitó dicha alternativa, pues lo que interesa es determinar qué explica la concentración del recaudo en impuestos como el IVA, por lo menos en la mayor parte de los noventa, independiente de cuál sea el nivel de la carga tributaria.

11 En su caso solo para identificar qué reformas han tenido éxito en incrementar el recaudo. 
Ecos de Economía

Universidad EAFIT

cierta regularidad en el comportamiento de los elementos del sistema tributario, ello no implica que otros factores de tipo contextual o estructural no intervengan, entre otras cosas afectando las bases gravables y la disposición de los contribuyentes para cumplir con sus obligaciones.

Las dos primeras variables endógenas mencionadas (\%IVA y \%ISR) son una innovación de este estudio, pues no se considera el recaudo que se obtiene de cada fuente, lo cual es una práctica común en la literatura que puede generar una sobreestimación de la importancia de factores como el PIB per cápita (dada su conocida relación con la PT), sino las participaciones del IVA y los ISR en los ingresos tributarios. Por su parte, el modelo de variable discreta que se utiliza para explicar Reforma sirve para confirmar la asociación entre GS y \%IVA, ya que si bien se encuentra que parte de la mayor dependencia del IVA pudo deberse a ciertas reformas, se analiza si estas últimas se dieron en periodos caracterizados, por ejemplo, por crecimientos del GS.

La tabla 2 presenta las variables utilizadas en esta sección, que corresponden a factores socioeconómicos, demográficos y políticos, junto a sus definiciones y las respectivas fuentes. Además, para establecer el efecto de las diferentes reformas aprobadas desde 1970, en términos de estructura y PT, se sugieren algunas estimaciones en que se incorporan dummies, una por cada reforma ${ }^{12}$, aunque más adelante solo se presentan los modelos en que todas las variables exógenas fueron estadísticamente significativas, al menos a un $90 \%$ de confianza.

Algunos elementos de la tabla 2 que merecen una justificación para ser incluidos son: en lo económico, Ahorro_dom y Form_capital; en el caso de las variables demográficas y sociales, Dens_pob y Pob_mayor; y para los factores políticos, Poder_gob, Ciclo_electoral y Democracia. Al respecto, Ahorro_dom supone una postergación del consumo y consecuentemente una reducción de la base del IVA, mientras que la relación no es clara en cuanto a Form_capital, pues podría reducir la participación de los ISR en el recaudo, dados los incentivos a la inversión que abundan en la legislación tributaria, pero también podría aumentarla si se acompaña de mayores retornos.

12 Las dummies en general se introdujeron con un rezago debido a que las reformas tradicionalmente consideran un periodo de transición o aplican para los siguientes periodos fiscales, a excepción de las comentadas en la nota que acompaña a la tabla 3. 
El gasto social como factor que favorece una mayor dependencia del IVA.

Un análisis para el caso colombiano

VÍCTOR MAURICIO CASTAÑEDA RODRÍGUEZ

Tabla 2.

Variables empleadas en el estudio

\begin{tabular}{|c|c|c|}
\hline Variable & Definición & Fuente \\
\hline $\begin{array}{l}\text { \%IVA, \%ISR, PT, } \\
\text { Reforma }\end{array}$ & $\begin{array}{l}\text { Variables endógenas. \%IVA y \%ISR son las participa- } \\
\text { ciones de estos impuestos en la presión tributaria } \\
\text { (PT), y Reforma es la probabilidad de que haya una } \\
\text { reforma con efectos sobre \%IVA. }\end{array}$ & $\begin{array}{l}\text { DIAN y Banco de la } \\
\text { República }\end{array}$ \\
\hline Log (PIB_per) & $\begin{array}{l}\text { Logaritmo del PIB per cápita (en pesos constantes de } \\
\text { 2005). }\end{array}$ & \multirow[t]{2}{*}{$\begin{array}{l}\text { Banco de la Repú- } \\
\text { blica }\end{array}$} \\
\hline Déficit & Déficit o superávit del Gobierno central & \\
\hline Ahorro_dom & Ahorro doméstico (\% del PIB) & \multirow{12}{*}{$\begin{array}{l}\text { Banco Mundial } \\
\text { (World Development } \\
\text { Indicators - WDI) }\end{array}$} \\
\hline Infl & $\begin{array}{l}\text { Inflación según la variación de los precios al consu- } \\
\text { midor (\%) }\end{array}$ & \\
\hline Apertura & $\begin{array}{l}\text { Suma de las exportaciones y las importaciones (\% del } \\
\text { PIB) }\end{array}$ & \\
\hline Deuda_ext & Deuda externa total (\% de las exportaciones) & \\
\hline Agric & Tamaño del sector agrícola (\% del PIB) & \\
\hline Manufactura & Tamaño del sector manufacturero (\% del PIB) & \\
\hline Form_capital & Formación bruta de capital (\% del PIB) & \\
\hline Recursos_nat & $\begin{array}{l}\text { Exportaciones de combustibles, oro, metales y comi- } \\
\text { da (\% exportaciones de mercancías) }\end{array}$ & \\
\hline Desempleo & Tasa de desempleo (\%) & \\
\hline Pob_rural & Población rural (\% población total) & \\
\hline Pob_mayor & Población mayor de 65 años (\% población total) & \\
\hline Dens_pob & $\begin{array}{l}\text { Densidad poblacional (personas por kilómetro cua- } \\
\text { drado de área) }\end{array}$ & \\
\hline GS & Gasto social (\% del PIB) & DNP \\
\hline Poder_gob & $\begin{array}{l}\text { Número relativo de escaños en la Cámara de Repre- } \\
\text { sentantes que corresponden al partido (o alianza) de } \\
\text { gobierno (\%) }\end{array}$ & $\begin{array}{l}\text { Banco Mundial (Da- } \\
\text { tabase of Political } \\
\text { Institutions - DPI) }\end{array}$ \\
\hline Democracia & $\begin{array}{l}\text { Índice combinado de democracia. El rango va de }-10 \\
\text { (altamente autocrático) a } 10 \text { (altamente democrático) }\end{array}$ & Polity IV \\
\hline $\begin{array}{l}\text { Variables de in- } \\
\text { tervención }\end{array}$ & Una variable dummy por cada año de reforma & \multirow{2}{*}{$\begin{array}{l}\text { Elaboración propia } \\
\text { con base en la ley } \\
\text { tributaria y los cam- } \\
\text { bios de gobierno }\end{array}$} \\
\hline Ciclo_electoral & $\begin{array}{l}\text { Dummy que toma un valor igual a } 1 \text { durante el primer } \\
\text { año de gobierno tras elecciones ejecutivas }\end{array}$ & \\
\hline
\end{tabular}

Fuente: elaboración propia con base en revisión de la literatura. 
Ecos de Economía

Universidad EAFIT

La densidad poblacional reduce los costos de administración y facilita el control a la evasión (Dioda, 2012), mientras que una alta proporción de población mayor de 65 años supone una mayor recaudación, especialmente en lo que respecta a los ISR, dado que las personas mayores tienden a exhibir una mayor moral tributaria (véase Torgler \& Schaltegger, 2005). Respecto al poder del partido de gobierno, según su participación en el número de escaños de la Cámara de Representantes, este es un factor que facilita, siempre y cuando haya disciplina partidista, la introducción de medidas regresivas (e. g., el alza de la tasa general del IVA); del mismo modo, el ciclo electoral limita el diseño y alcance de las políticas, de suerte que se espera que al comienzo del periodo de gobierno sea más probable el aumento de los impuestos indirectos, pues lo normal es que un presidente pierda popularidad progresivamente (véase e. g., Ashworth \& Heyndels, 2002). Finalmente, un alto grado de democracia indica una relación fluida entre el Estado y los ciudadanos, lo que a su vez soporta la idea de un mayor cumplimiento tributario. ${ }^{13}$

La tabla 3 presenta las estimaciones MCO de algunos modelos dinámicos. Sin embargo, antes de analizar los resultados es necesario desmentir la potencial existencia de relaciones espurias, por lo que se debe establecer qué variables están cointegradas, considerando su componente temporal.

Para ello, inicialmente se determina qué variables no son estacionarias, lo que significa identificar aquellas con un orden de integración mayor o igual a 1. En la tabla 4, que solo toma los factores del modelo 3 (tabla 3), dado que este documento busca fundamentar principalmente la relación entre \%IVA y GS, se observa que a excepción de Form_capital y Pob_rural, las demás series no son estacionarias, según la prueba de Dickey Fuller aumentada.

13 Dioda (2012) en un trabajo empírico para AL y el Caribe, pero utilizando el índice construido por Freedom House, encuentra que existe una relación positiva y significativa entre la extensión de las libertades políticas y el recaudo por impuestos directos. 


\section{4}

El gasto social como factor que favorece una mayor dependencia del IVA.

Un análisis para el caso colombiano

VÍCTOR MAURICIO CASTAÑEDA RODRÍGUEZ

Tabla 3.

Resultados econométricos

\begin{tabular}{|c|c|c|c|c|c|c|}
\hline \multirow{2}{*}{$\begin{array}{c}\text { Método de } \\
\text { estimación } \\
\text { Modelo }\end{array}$} & \multicolumn{5}{|c|}{ MCO } & \multirow{2}{*}{$\begin{array}{c}\text { Probit } \\
6\end{array}$} \\
\hline & 1 & 2 & 3 & 4 & 5 & \\
\hline & \%ISR & \%ISR & \%IVA & \%IVA & PT & Reforma \\
\hline $\begin{array}{l}\text { Variable dependiente } \\
\text { rezagada }\end{array}$ & $0,49^{* * *}$ & $0,49^{* * *}$ & $0,60^{* * *}$ & $0,70^{* * *}$ & $0,78^{* * *}$ & \\
\hline Log (PIB per cápita) & & & & & $0,09^{*}$ & \\
\hline Form_capital & $-0,33^{*}$ & & $0,25^{* *}$ & & & \\
\hline Ahorro_dom & & & $-0,49^{* * *}$ & & & \\
\hline Infl & & & & & $-0,02^{* *}$ & \\
\hline Agric & & & & & $-0,07^{* * *}$ & \\
\hline Manufactura & $-0,79^{* * *}$ & $-0,48^{* * *}$ & $0,70^{* *}$ & & & \\
\hline$\Delta$ Déficit (-1) & & & & & $0,13^{* * *}$ & \\
\hline Apertura & & & & & $0,06^{* * *}$ & \\
\hline GS & & & $0,76^{* * *}$ & $0,46^{* * *}$ & & \\
\hline Pob_rural & $0,57^{* * *}$ & $0,58^{* * *}$ & $-0,63^{* * *}$ & $-0,24^{* * *}$ & & \\
\hline Pob_mayor & $1,73^{*}$ & $2,53^{* * *}$ & & & & \\
\hline $\begin{array}{l}\text { Crecimiento del gasto } \\
\text { social }\end{array}$ & & & & & & $6,86^{* *}$ \\
\hline $\begin{array}{l}\text { Crecimiento de la } \\
\text { inflación }\end{array}$ & & & & & & $-2,76^{\star *}$ \\
\hline Recaudo ByS(-1) & & & & & & $-0,006^{* * *}$ \\
\hline Democracia & $2,21^{* *}$ & & $2,51 * * *$ & $1,89^{* * *}$ & & \\
\hline \multicolumn{7}{|l|}{$\begin{array}{l}\text { Variables de interven- } \\
\text { ción }\end{array}$} \\
\hline Reforma de 1974(-1) & & $4,85^{\text {** }}$ & & & $1,35 * * *$ & \\
\hline Reforma de $1983(-1)$ & & $7,10^{* * *}$ & & $2,70^{*}$ & & \\
\hline Reforma de $1986(-1)$ & & & & & $0,50 *$ & \\
\hline Reforma de 1990(-1) & & $11,3^{* * *}$ & & & & \\
\hline Reforma de $1992(-1)$ & & $6,99^{* * *}$ & & $4,36^{* * *}$ & & \\
\hline Reforma de 1995(-1) & & & & $5,04^{* * *}$ & & \\
\hline Reforma de 2000(-1) & & & & & $1,09^{*}$ & \\
\hline Reforma de 2002(-1) & & & & $2,73^{*}$ & & \\
\hline
\end{tabular}


Ecos de Economía

Universidad EAFIT

No 38 - Vol. 18 / enero-junio 2014

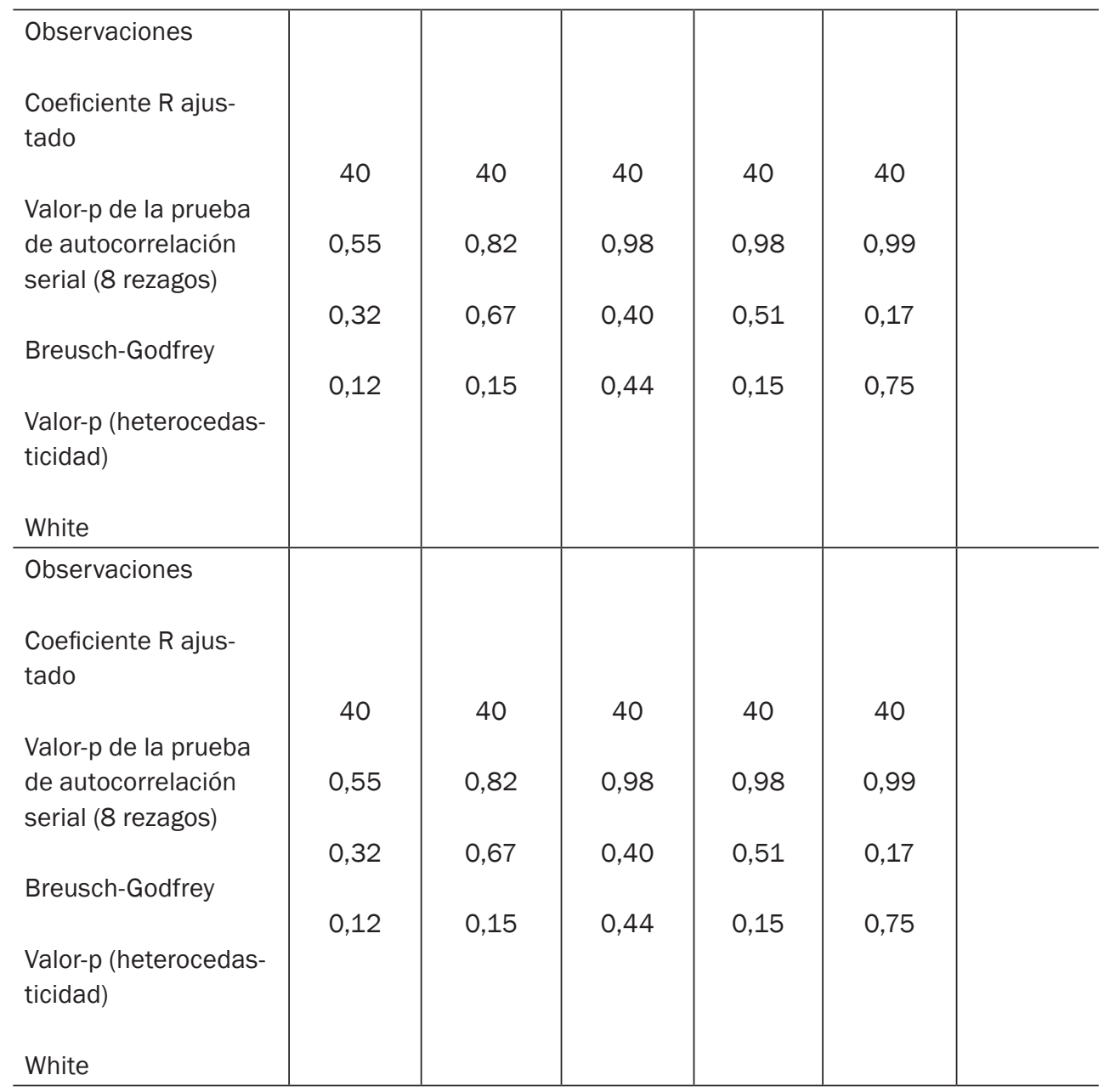

Fuente: elaboración propia. * Significativo al 10\%, ** Significativo al 5\%, *** Significativo al 1\%. En el modelo 2 se utilizaron las dummies para las reformas de 1983 y 1992 sin rezago, pues fueron aprobadas y ratificadas antes de mitad de año e introdujeron ajustes inmediatos. Para el modelo 6 , el criterio de información de Akaike-AIC $=0,74$, Count $\mathrm{R} 2=0,93$ y Count $\mathrm{R} 2$ ajustado $=$ 0,50. Las variables se dejaron en porcentajes cuando expresaban una proporción. 
El gasto social como factor que favorece una mayor dependencia del IVA.

Un análisis para el caso colombiano

VÍCTOR MAURICIO CASTAÑEDA RODRÍGUEZ

Tabla 4.

Test de estacionariedad

\begin{tabular}{c|c|c}
\hline \multicolumn{2}{c}{ Test de Dickey Fuller aumentado: La serie tiene una raíz unitaria } \\
\hline Serie & Valor $\mathbf{p}$ & Orden de integración \\
\hline \%ByS & 0,972 & $\mathrm{I}(1)$ \\
\hline Manufactura & 0,929 & $\mathrm{I}(1)$ \\
\hline Ahorro_dom & 0,378 & $\mathrm{I}(1)$ \\
\hline Form_capital Gasto_soc & 0,041 & $\mathrm{I}(0)$ \\
\hline Rural_pob & 0,895 & $\mathrm{I}(1)$ \\
Democracia & 0,093 & $\mathrm{I}(0)$ \\
\hline
\end{tabular}

Fuente: elaboración propia con base en datos de la DIAN, Banco Mundial, DNP y Polity IV. Orden de integración definido a un nivel de confianza del $90 \%$.

Para analizar el tema de la cointegración, que se refiere a la potencial combinación de por lo menos dos series no estacionarias, de tal modo que se eliminen las tendencias estocásticas y los errores de su regresión sean I(0), se emplea el método de Johansen sobre \%IVA y GS (ambas I(1)). Este considera dos pruebas para determinar el número de vectores de cointegración, la prueba de la traza y la prueba del máximo valor propio. En términos económicos, si se encuentra que las dos series de interés están cointegradas (existe al menos un vector de cointegración), se puede argumentar que hay una relación a largo plazo, o de equilibrio, entre ambas (Gujarati, 2003, p. 796).

En efecto, si se emplean tres rezagos en el planteamiento de la relación temporal entre \%IVA y GS, dando así un horizonte temporal lo suficientemente amplio para que el cambio de alguna de estas variables encuentre eco en la otra, se tiene que para las especificaciones del método de Johansen presentadas en la tabla 5, existe evidencia de una relación de cointegración. ${ }^{14}$ Esto, entonces, fundamenta la existencia de una asociación a largo plazo entre las dos series y apoya la hipótesis planteada por este documento, sobre la capacidad de explicar el aumento de la dependencia tributaria del IVA en Colombia a través de la dinámica del GS.

14 Asimismo, si se analiza el número de relaciones de cointegración entre todas las series I(1) de la tabla 4, tomando también tres rezagos, se determina que hay entre 3 y 4, dependiendo de la especificación. 


\section{Tabla 5.}

Número de relaciones de cointegración entre \%IVA y Gasto social

\begin{tabular}{c|c|c|c}
\hline Tendencia & Ninguna & Lineal & Lineal \\
\hline $\begin{array}{c}\text { Especificación } \\
\text { prueba }\end{array}$ & Con Intercepto & Con Intercepto & Con Intercepto \\
\cline { 2 - 4 } & Sin tendencia & Sin tendencia & Con tendencia \\
\hline Traza & 1 & 1 & 1 \\
\hline $\begin{array}{c}\text { Máximo valor } \\
\text { propio }\end{array}$ & 1 & 1 & 1 \\
\hline
\end{tabular}

Fuente: elaboración propia con base en datos de la DIAN y el DNP.

Estando ahora en la posición de discutir las estimaciones de la tabla 3, es interesante notar que solo se incluyó como parámetro político al índice de democracia, pues los demás no fueron significativos, pese a probar diferentes especificaciones. Por otro lado, el logaritmo del PIB per cápita, ${ }^{15}$ como proxy del desarrollo económico, no fue relevante en lo que atañe a estructura tributaria, pero sí lo fue cuando se tomó a la PT como variable endógena.

Según los primeros tres modelos de la tabla 3, Form_capital exhibe una asociación negativa (positiva) con \%ISR (\%IVA), lo que sugiere que los beneficios tributarios a la inversión pueden estar limitando el potencial de recaudo de los ISR y el grado de progresividad del sistema, pues estos tienden a concentrarse en los deciles más ricos (véase e. g., Steiner \& Cañas, 2013). Además, entre las variables económicas el único resultado que no parece intuitivo es el referente a Manufactura en el modelo 1, aunque no es robusto, ya que no se mantuvo en la mayoría de especificaciones alternativas.

Por su parte, Pob_rural, que comúnmente se asocia con dificultades de la administración tributaria e informalidad (e. g., Tanzi, 1987), guarda una relación negativa con \%IVA, y curiosamente positiva con \%ISR, lo que se justifica por prácticas comunes en el campo como el autoconsumo. Empero, los resultados conjuntos de los modelos 1, 2, 3 y 4 podrían estar presionados por el hecho de que \%ISR y \%IVA son razones que comparten el denominador, a saber la PT, de modo que el aumento de la dependencia en una de estas fuentes de ingreso eventualmente se haría a costa de la otra.

15 La utilización del logaritmo de esta variable es usual en la literatura, y se busca corregir el problema de escala y prevenir la heterocedasticidad. 


\section{8}

EI gasto social como factor que favorece una mayor dependencia del IVA.

Un análisis para el caso colombiano

VÍCTOR MAURICIO CASTAÑEDA RODRÍGUEZ

El modelo 3 (tabla 3), que no controla por reformas, es coherente con lo discutido en las secciones anteriores, en lo que respecta a la relación entre GS y \%IVA, particularmente por el potencial del primero para facilitar el cumplimiento y aceptación de los contribuyentes de una mayor PT a través de impuestos indirectos. ${ }^{16}$ De otro lado, el GS no es relevante en las estimaciones que toman a \%ISR como variable dependiente, cosa que es importante rescatar, pues si el coeficiente del modelo 1 fuera estadísticamente significativo y mayor que el del modelo 3 , por ejemplo, entonces buena parte de la argumentación de este documento perdería sustento.

En cuanto a la incidencia de las reformas tributarias, es llamativo que la correspondiente a 1990 únicamente tenga un efecto positivo sobre \%ISR. Son las reformas de 1983 , 1992, 1995 y 2002 las que significativamente se relacionan con un aumento de \%IVA (modelo 4); las primeras tres modificaron la tasa general del IVA: en 1983 se estableció una tarifa única del 10\% y luego, por medio de las leyes 6 de 1992 y 223 de 1995, se fijó en 14 y 16\%, respectivamente (en estos años el GS también creció notoriamente).

El modelo probit numerado como 6 toma a Reforma como variable dependiente, esta es una dummy igual a 1 en los años de aprobación de las leyes con un efecto positivo sobre \%IVA. Se observa que el crecimiento del GS supone una mayor probabilidad de ocurrencia de este tipo de reformas, lo que es coherente con la argumentación del artículo; por otro lado, el recaudo previo del IVA (como porcentaje del PIB) y el crecimiento de la inflación la reducen. Lo últimos resultados son razonables si se considera que a medida que aumenta la dependencia de una fuente se acotan las posibilidades de continuar haciéndolo, y que la inflación constituye en el corto plazo un sustituto de los impuestos tradicionales.

En lo que a PT se refiere, los coeficientes estimados están en línea con la literatura (véase e. g., Dioda, 2012; Mahdavi, 2008; Davoodi \& Grigorian, 2007; Cetrángolo \& Gómez, 2007b; Bahl, 2004; Piancastelli, 2001; Tanzi \& Davoodi, 2000); la agricultura y la inflación se acompañan de un coeficiente negativo y significativo en el modelo 5 , mientras que el logaritmo del PIB per cápita y el comportamiento del déficit en el periodo anterior tienen signo positivo. Además, se establece que en su mayoría son aquellas re-

16 Es importante rescatar que se probaron relaciones no lineales en este caso, incluyendo la potencia cuadrática y cúbica del GS, pero los respectivos coeficientes no fueron estadísticamente significativos. 
Ecos de Economía

Universidad EAFIT

formas tributarias con calidad de estructurales, ${ }^{17}$ caso de las correspondientes a 1974 y 1986, las que han incrementado la recaudación del Gobierno central; la relevancia de la Ley 633 del 2000 puede deberse a las medidas adoptadas para el cálculo de la renta presuntiva, al incremento de la tasa general del IVA (nuevamente al 16\%) y a las modificaciones del GMF, que formalmente se incorporó al ET.

Si bien el análisis de la PT no es objetivo central de este documento, es importante subrayar que los hallazgos comentados en el párrafo previo difieren de las conclusiones de autores como García y Gómez (2005), quienes encuentran que las reformas de 1974 y 1990 fueron las únicas satisfactorias en su objetivo de aumentar el recaudo; asimismo, Sánchez y Gutiérrez (1995), aunque determinan que las leyes tributarias aprobadas entre 1980 y 1992 no fueron completamente exitosas, sugieren que las correspondientes a 1983 y 1990 habrían ayudado a incrementar la PT.

En todo caso, la tabla 3 indica que son más las reformas que han modificado la estructura impositiva que las que han incrementado la PT, de manera que la evolución de la última se asocia especialmente con la dinámica de factores económicos (e. g., Infl y Agric); también es curioso que no aparezcan medidas tributarias asociadas negativamente con las variables endógenas, de suerte que aquellas que buscaron el alivio fiscal, como la de 1979, o bien fueron compensadas por aumentos de impuestos diferentes a los tratados en esta sección, o no tuvieron un efecto significativo.

Por último, una preocupación en este tipo de ejercicios es la endogeneidad, ${ }^{18}$ que en caso de presentarse conduce a estimadores sesgados e inconsistentes. En particular, se plantea verificar si el GS es efectivamente exógeno, pues es razonable, por otro lado, que la alta participación del IVA en el recaudo total indique una importante capacidad administrativa del Estado y una fortaleza para implementar programas sociales, por ejemplo.

Se debe asumir que el modelo econométrico incurre en endogeneidad, encontrar la solución y posteriormente verificar si el problema se presenta efectivamente; esto supone aplicar las pruebas de hipótesis al final y no al comienzo, como es usual. Consecuente-

17 Que además brillan por su ausencia desde los noventa.

18 Esta puede surgir a causa de la omisión de variables relevantes, simultaneidad, error de medición y sesgo de selección. 


\section{0}

El gasto social como factor que favorece una mayor dependencia del IVA.

Un análisis para el caso colombiano

VÍCTOR MAURICIO CASTAÑEDA RODRÍGUEZ

mente, se emplea el método de mínimos cuadrados en dos etapas (MC2E) y se toma la tasa bruta de matrícula en educación secundaria, Pob_mayor y el logaritmo del PIB_per como instrumentos del GS. Otros estudios sostienen que existe una relación positiva entre educación y participación política de los ciudadanos (Galston, 2001), lo que sería un factor de presión para la creación de programas sociales, mientras que las otras dos variables dan cuenta de los mayores costos que supone atender la vejez, especialmente en lo que atañe a pensiones y salud, y la caracterización de los bienes públicos como superiores (ley de Wagner).

Tras tomar el modelo 3 (tabla 3) como referencia y estimarlo alternativamente por MC2E, se confirmó la relevancia de los instrumentos observando su significancia individual en la regresión de la primera etapa:19 también se verificó su validez con la prueba de restricciones sobreidentificadas de Sargan (Valor-p de 0,14). No obstante lo anterior, la prueba de Hausman permitió concluir, al no rechazarse la hipótesis nula de exogeneidad (Valor-p fue 0,39), que la estimación original (MCO) era consistente y no se requería de variables instrumentales, en tanto el GS era exógeno; por esto no se presenta al final la estimación por MC2E.

\section{Conclusiones}

La dinámica de la tributación en un país no responde solo a la introducción de reformas, sino que además los cambios de factores estructurales o del contexto en que se realizan las interacciones entre los ciudadanos y el Estado, influyen. Así, uno de los instrumentos que puede facilitar la introducción de medidas que incrementan la carga tributaria a través de impuestos indirectos, y su aceptación, es el gasto, en particular aquel que se destina a sectores como la educación, la salud y la seguridad social, por su visibilidad con relación a otras categorías (e. g., gasto en funcionamiento). Las estimaciones sugieren que un aumento del gasto social en $1 \%$ del PIB se asocia, por lo menos, con un incremento de la dependencia de la recaudación en el IVA (\%IVA) de 0,5\%.

Por otra parte, son pocas las reformas tributarias que han tenido un efecto real, tras descontar la influencia de características estructurales como el tamaño del sector agrí-

19 En la primera etapa se debe explicar el gasto social (GS) usando como regresores a todas las demás variable exógenas de la especificación inicial junto a los instrumentos. La segunda etapa de la metodología consiste en utilizar los pronósticos del GS, en lugar de sus observaciones, para estimar el modelo original. 
cola, sobre el recaudo. Según este estudio, las reformas de 1974, 1986 y 2000 contribuyeron a una mayor PT, de las cuales solamente las dos primeras se pueden catalogar como estructurales. No es de extrañar, entonces, que sean pocos los avances en términos de suficiencia fiscal, pues muchas de las leyes aprobadas en los últimos veinte años han sido en buena parte una colcha de retazos, en que si bien se incrementa el recaudo de algunas fuentes, también se ceden recursos vía exenciones tributarias (e. g., la deducción por inversión en activos productivos).

En Colombia no ha sido posible, en los últimos veinticinco años, que los poderes políticos y económicos alcancen un acuerdo que permita aprobar reformas tributarias de tipo estructural, a pesar de que sus contextos de discusión han sido más favorables en comparación con la experiencia de otros países de la región. Las motivaciones de las innovaciones tributarias han estado estrechamente vinculadas con problemas circunstanciales, por lo general relacionados con incrementos del déficit fiscal, y además se ha hecho complejo el sistema, pues es normal que se busque que parte del incremento del recaudo esperado tras las modificaciones de determinadas fuentes financien los beneficios asignados en otras.

Los incrementos del GS, en particular durante la primera mitad de los noventa, generaron una oportunidad para que el recaudo se concentrara en el IVA, dado que grava a una diversidad de agentes, entre quienes se encuentran los que mayor utilidad perciben de las partidas presupuestales asignadas a áreas como la educación básica, pues de otra forma quedarían excluidos del sistema. En este orden de ideas, reformas como las de 1992 y 1995, que aumentaron la tasa general del IVA e implicaron una mayor dependencia de esta fuente, son más probables cuando las erogaciones sociales crecen; esto sugiere una dosis de pragmatismo de los gobiernos a la hora de identificar con qué instrumentos financian sus programas o las demandas sociales. Es más fácil defender una política tributaria regresiva cuando lo que se financia supone una alta utilidad para los individuos que se ubican en los deciles inferiores del ingreso.

\section{Referencias}

Agudelo, C.; Cardona, J.; Ortega, J. y Robledo, R. (2011). Sistema de salud en Colombia: 20 años de logros y problemas. Ciência \& Saúde Coletiva, 16(6), 2817-28. 
El gasto social como factor que favorece una mayor dependencia del IVA.

Un análisis para el caso colombiano

VÍCTOR MAURICIO CASTAÑEDA RODRÍGUEZ

Alm, J. y Martínez-Vázquez, J. (2007). Tax morale and tax evasion in Latin America (Working paper). Georgia, EE. UU.: Andrew Young School of Policy Studies.

Ashworth, J. y Heyndels, B. (2002). Tax structure turbulence in OECD countries. Public Choice, 111, 347-76.

Avendaño, N. (2005). Evasión en el impuesto a la renta de personas naturales: Colombia 1970-1999. Archivos de Economía, 295.

Bahl, R. W. (2004). Reaching the hardest to tax: Consequences and possibilities. En J. Alm, J. Martínez y S. Wallace (Eds.), Taxing the hard-to-tax: Lessons from theory and practice (pp. 336-354). Amsterdam, Holanda: Emerald Group Publishing Limited.

Bird, R.; Martínez-Vázquez, J. y Torglel, B. (2008). Tax effort in developing countries and high income Countries: the impact of corruption, voice and accountability. Economic Analysis and Policy, 38(1), 55-71.

Calderón, V. y González, F. (2002). Las reformas tributarias en Colombia durante el siglo XX (II). Boletines de Divulgación Económica. Bogotá, Colombia: DNP.

Cárdenas, M.; Junguito, R. y Pachón, M. (2006). Political institutions and policy outcomes in Colombia: the effects of the 1991 constitution. (Working Paper). Washington, EE. UU.: Inter-American Development Bank.

Castañeda, V. (2013). La tributación en América Latina desde la crisis de la deuda y el papel del legislativo en Colombia. Revista de Economía Institucional, 28(1), 257-80.

Castañeda, V. (2012). Una revisión de los determinantes de la estructura y el recaudo tributario: el caso latinoamericano tras la crisis de la deuda externa. Cuadernos de Economía, 57.

Cetrángolo, O. y Gómez-Sabaini, J. (Comps.) (2007). Tributación en América Latina: en busca de una nueva agenda de reformas. Santiago, Chile: Cepal.

Clavijo, S. (2001). Fallos y fallas de la Corte Constitucional: el caso de Colombia 19912000. Bogotá, Colombia: Alfaomega.

Clavijo, S. (2005). Tributación, equidad y eficiencia en Colombia: guía para salir de un sistema tributario amalgamado. Borradores de Economía, 325. 
Davoodi, H. y Grigorian, D. (2007). Tax potential vs. tax effort: a cross-country analysis of Armenia's stubbornly low tax collection. (Working paper). Washington, EE. UU.: IMF.

Dioda, L. (2012). Structural determinants of tax revenue in Latin America and the Caribbean: 1990-2009. (Working Paper). México D. F., México: Cepal.

Edwards, S. y Steiner, R. (2000). La economía política de las reformas estructurales: lecciones de la experiencia colombiana 1989-1999. Bogotá, Colombia: Fedesarrollo.

Frey, B. y Feld, L. (2002). Deterrence and morale in taxation: an empirical analysis. (Working paper). Munich, Alemania: CESifo.

Galindo A. y Meléndez, M. (2010). Corporate tax stimulus and investment in Colombia. (Working Paper). Washington, EE. UU.: Inter-American Development Bank.

Galston, W. (2001). Political knowledge, political engagement, and civic education. Annual Review of Political Science, 4, 217-34.

García, M. y Gómez, A. (2005). ¿Han aumentado el recaudo las reformas tributarias en Colombia? Revista de economía institucional, 7(12), 43-61.

Gaviria, A.; Medina, C. y Mejía, C. (2006). Evaluating the impact of health care reform in Colombia: from theory to practice. Documentos CEDE. Bogotá: Universidad de los Andes.

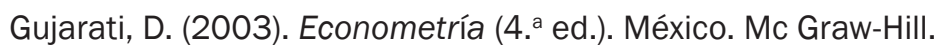

Gupta, A. (2007). Determinants of tax revenue efforts in developing countries (Working Paper). Washington, EE. UU.: FMI.

Hettich, W. y Winer, S. (1988). Economic and political foundations of tax structure. American Economic Review, 78(4), 701-12.

Icfes (2011). Examen de Estado de la educación media. Resultados del periodo 20052010. Recuperado de: https://icfesdatos.blob.core.windows.net/datos/Informe\%20resultados\%20historicos\%20Saber\%2011\%202005-2010.pdf

Iregui, A.; Melo, L. y Ramos, J. (2007). Evaluación y análisis de eficiencia de la educación en Colombia. Revista de Economía del Rosario, 10(1), 21-41. 


\section{4}

El gasto social como factor que favorece una mayor dependencia del IVA.

Un análisis para el caso colombiano

VÍCTOR MAURICIO CASTAÑEDA RODRÍGUEZ

Junguito, R. y Rincón, H. (2004). La política fiscal en el siglo XX en Colombia. Documento preparado para el seminario "Investigaciones recientes sobre historia económica colombiana", en Bogotá, Colombia.

Leonardo, G. (2011). Politics and tax morale. The role of trust, values, and beliefs, in shaping individual attitudes towards tax compliance. (Tesis de doctorado). Georgia State University, Georgia.

López, H. y Núñez, J. (2007). Pobreza y desigualdad en Colombia. Diagnóstico y estrategias. Bogotá, Colombia: DNP.

Mahdavi, S. (2008). The level and composition of tax revenue in developing countries: evidence from unbalanced panel data. International Review of Economics and Finance, 17, 607-17.

Moller, L. (2012). Fiscal policy en Colombia. Tapping its potential for a more equitable society. (Working paper). Washington: The World Bank.

Olivera, M.; Pachón, M. y Perry, G. (2010). The political economy of fiscal reform: the case of Colombia, 1986-2006. (Working Paper). Washington, EE. UU.: Inter-American Development Bank.

Piancastelli, M. (2001). Measuring the tax effort of developed and developing countries. Cross country panel data analysis: 1985/1995. Río de Janeiro, Brasil: Instituto de Pequisa Economica Aplicada.

Rosas, G. (1990). Apuntes sobre finanzas públicas. Bogotá, Colombia: Seguros Colmena.

Sánchez, O. (2006). Tax system reform in Latin America: domestic and international causes. Review of International Political Economy, 13(5), 772-801.

Sánchez, F. y Gutiérrez, C. (1995). Casos de éxito de reformas fiscales en Colombia: 1980-1992. Serie Política Fiscal, 71. Cepal y PNUD.

Steiner, R. y Cañas, A. (2013). Tributación y equidad en Colombia. Bogotá, Colombia: Universidad de los Andes-CEDE.

Steiner, R. y Soto, C. (1998). IVA: productividad, evasión y progresividad. (Working Paper). Bogotá, Colombia: Fedesarrollo. 
Tanzi, V. y Davoodi, H. (2000). Corruption, growth and public finance. (Working Paper). Washington, EE. UU.: FMI.

Tanzi, V. (1987). Quantitative characteristics of tax systems of developing countries. En Newbery y Stern (Eds.), The theory of taxation for developing countries. Nueva York, EE. UU.: Oxfort University Press.

Torgler, B. (2005). Tax morale in Latin America. Public Choice, 122(1/2), 133-57.

Torgler, B. y Schaltegger, C. (2005). Tax moral and fiscal policy. (Working Paper). GeIlertstrasse, Alemania: Center for Research in Economics, Management and the Arts (Crema).

Torgler, B. y Schneider, F. (2007). What shapes attitudes toward paying taxes? Evidence from multicultural European countries. Social Science Quarterly, 88(2), 443-470.

Wiesner, E. (2004). El origen político del déficit fiscal en Colombia: el contexto institucional 20 años después. Documento preparado para la sesión inaugural de la XXVIII Jornada Tributaria del Instituto Colombiano de Derecho Tributario, en Cartagena, Colombia. 